\title{
Trends in morphine prescriptions, illicit morphine use and associated harms among regular injecting drug users in Australia
}

\author{
LOUISA DEGENHARDT ${ }^{1}$, EMMA BLACK ${ }^{1}$, COURTNEY BREEN ${ }^{1}$, RAIMONDO BRUNO ${ }^{2}$, \\ STUART KINNER ${ }^{3}$, AMANDA ROXBURGH ${ }^{1}$, CRAIG FRY ${ }^{4}$, REBECCA JENKINSON ${ }^{4}$, \\ JEFF WARD ${ }^{5}$, JAMES FETHERSTON ${ }^{6}$, JOSEPHINE WEEKLEY ${ }^{7}, \&$ JANE FISCHER $^{3}$
}

\author{
${ }^{1}$ National Drug and Alcohol Research Centre, University of NSW, New South Wales, ${ }^{2}$ School of Pharmacy and School of \\ Psychology, University of Tasmania, Tasmania, ${ }^{3}$ Queensland Alcohol and Drug Research and Education Centre, University \\ of Queensland, Queensland, ${ }^{4}$ Turning Point Alcohol and Drug Centre, Victoria, ${ }^{5}$ School of Psychology, Australian National \\ University, Australian Capital Territory, ${ }^{6}$ National Drug Research Institute, Curtin University, Western Australia, and \\ ${ }^{7}$ Drug and Alcohol Services South Australia, South Australia, Australia
}

\begin{abstract}
This paper examines population trends in morphine prescriptions in Australia, and contrasts them with findings from annual surveys with regular injecting drug users (IDU). Data on morphine prescriptions from 1995 to 2003 were obtained from the Drug Monitoring System (DRUMS) run by the Australian Government Department of Health and Ageing. Data collected from regular IDU as part of the Australian Illicit Drug Reporting System (IDRS) were analysed (2001-2004). The rate of morphine prescription per person aged 15-54 years increased by 89\% across Australia between 1995 and 2003 (from 46.3 to $85.9 \mathrm{mg}$ per person). Almost half (46\%) of IDU surveyed in 2004 reported illicit morphine use, with the highest rates in jurisdictions where heroin was less available. Recent morphine injectors were significantly more likely to be male, unemployed, out of treatment and homeless in comparison to IDU who had not injected morphine. They were also more likely to have injected other pharmaceutical drugs and to report injection related problems. Among those who had injected morphine recently, the most commonly reported injecting harms were morphine dependence (38\%), difficulty finding veins into which to inject (36\%) and scarring or bruising (27\%). Morphine use and injection is a common practice among regular IDU in Australia. In some cases, morphine may be a substitute for illicit heroin; in others, it may be being used to treat heroin dependence where other pharmacotherapies, such as methadone and buprenorphine, are perceived as being unavailable or undesirable by IDU. Morphine injection appears to be associated with polydrug use, and with it, a range of problems related to drug injection. Further research is required to monitor and reduce morphine diversion and related harms by such polydrug injectors. [Degenhardt $\mathrm{L}$, Black E, Breen C, Bruno R, Kinner S, Roxburgh A, Fry C, Jenkinson R, Ward J, Fetherston J, Weekley J, Fischer J. Trends in morphine prescriptions, illicit morphine use and associated harms among regular injecting drug users in Australia. Drug Alcohol Rev 2006;25:403-412]
\end{abstract}

Key words: heroin, injecting drug user, morphine, overdose, pharmaceutical drug.

\section{Introduction}

The use of diverted prescription drugs has received increasing attention in recent years, perhaps due to indications of increased harms related to their use.
In the United States, for example, emergency departments (ED) recorded an increase in the number of benzodiazepine mentions from 88808 in 1998 to 105752 in 2002 [1], and use among young people has been a cause of increasing concern $[2,3]$.

\footnotetext{
Louisa Degenhardt PhD, National Drug and Alcohol Research Centre, University of NSW, New South Wales, Australia, Emma Black, National Drug and Alcohol Research Centre, University of NSW, New South Wales, Australia, Courtney Breen, National Drug and Alcohol Research Centre, University of NSW, New South Wales, Australia, Raimondo Bruno, School of Pharmacy and School of Psychology, University of Tasmania, Tasmania, Stuart Kinner PhD, Queensland Alcohol and Drug Research and Education Centre, University of Queensland, Queensland, Australia, Amanda Roxburgh, National Drug and Alcohol Research Centre, University of NSW, New South Wales, Australia, Craig Fry, Turning Point Alcohol and Drug Centre Inc., Victoria, Australia, Rebecca Jenkinson, Turning Point Alcohol and Drug Centre Inc., Victoria, Australia, Jeff Ward PhD, School of Psychology, Australian National University, Australian Capital Territory, Australia, James Fetherston, National Drug Research Institute, Curtin University, Western Australia, Josephine Weekley, Drug and Alcohol Services South Australia, South Australia, Jane Fischer, Queensland Alcohol and Drug Research and Education Centre, University of Queensland, Queensland, Australia. Correspondence to Louisa Degenhardt, National Drug and Alcohol Research Centre, University of New South Wales, Sydney, NSW 2052, Australia. Tel: +61 (0)2 9385 0333; Fax: +61 (0)2 9385 0222; E-mail: 1.degenhardt@unsw.edu.au
}

Received 13 July 2005; accepted for publication 21 April 2006. 
There are many potential harms associated with using diverted prescription drugs, particularly related to the injection of compounds designed for oral administration. For instance, benzodiazepine injection has been associated with significant injection related problems [4-8], and methadone injection has also been investigated $[9,10]$. Several studies have documented the diversion and injection of buprenorphine by injecting drug users (IDU) following its introduction in France [11-13]. Other studies have examined the role of prescription medication in drug-induced deaths and found that these drugs are often implicated in overdose and death [14-16].

While there has been less evaluation of the diversion and illicit use of morphine preparations [17], increasing use of diverted prescription opioids such as oxycodone has also been documented in the United States over the past decade [18]. Corroborative evidence of an increase in morphine misuse in the United States was given by a doubling of mentions of narcotic analgesics in EDs from 58946 to 119185 between 1998 and 2002 [1].

For a number of years, Australia has had systematic surveillance of illicit drug markets, including diverted prescription medications, particularly through the Illicit Drug Reporting System (IDRS) [19]. The IDRS incorporates surveys with regular IDU, who are considered to be a sentinel group of drug users within which emerging trends may be seen before spreading to other groups of drug users. There are jurisdictional differences across Australia in patterns of prescription drug use. In jurisdictions where there have been extended periods of low availability of heroin, namely Tasmania (TAS) and the Northern Territory (NT), illicit morphine and methadone are used more commonly [20-22] than in jurisdictions where heroin is more readily available [such as New South Wales (NSW) and Victoria (VIC)] $[23,24]$. The lack of an opioid maintenance treatment programme in NT until 2002 is also likely to be a contributing factor in the use of illicit opioids in that jurisdiction [21].

Previous work from the IDRS and similar projects has investigated pharmaceutical drug use among regular IDU, particularly benzodiazepine, methadone and buprenorphine use [4,5,25,26]. Little is known, however, about the harms associated with injection of diverted morphine preparations. Little examination of trends in morphine use among IDU has been conducted in Australia, despite the wide range of formulations and doses available, and suggestive evidence that use may be increasing among regular IDU.

\section{Aims}

Because of the potential for harm from injecting diverted morphine preparations, this study aims to compare trends in population prescriptions of morphine with data from surveys of regular IDU interviewed as part of the IDRS. Specifically, we aimed to do the following:

- document the amount of morphine prescribed, and rates of morphine prescription across Australian jurisdictions (standardised by the population aged $15-54$ years);

- compare patterns and prevalence of use and injection of morphine and heroin by IDU;

- examine the demographic characteristics, drug use patterns and risk behaviours of recent morphine injectors, compared with IDU who reported no such use; and

- document the patterns of morphine related harms among recent morphine injectors.

\section{Method}

Prescription data

Data on morphine prescriptions from 1995 to 2003 were obtained from the Drug Monitoring System (DRUMS) run by the Australian Government Department of Health and Ageing. Data on the number of prescriptions by year and jurisdiction were collected for the following formulations: $10,15,30,60,100$ and $200 \mathrm{mg}$ controlled release tablets; 20,50 and $100 \mathrm{mg}$ controlled release capsules; and $30 \mathrm{mg}$ tablets.

\section{IDU data}

Research has demonstrated continually that extensive polydrug use is the norm among Australian IDU $[22,27,28]$. As such, IDU can be considered an appropriate 'sentinel' population to provide information on drug use patterns and trends. IDU survey data are not representative of illicit drug use in the general population, nor are they representative of all injecting drug users; they are indicative of emerging trends that warrant further monitoring.

Each year the IDRS is conducted in every jurisdiction across Australia. Data are presented here for the years 2001-2004. Approximate sample sizes for each jurisdiction each year were: New South Wales (NSW) and Victoria (VIC), $n=150$; NT, Queensland (QLD), Australian Capital Territory (ACT), South Australia (SA), TAS and Western Australia (WA), $n=100$ and reflect predetermined quotas. Full details of the demographic and methodological characteristics of each sample are available elsewhere [22,27,29-32]. IDU were interviewed between June and August of each year. Eligibility criteria were: at least monthly injection in the preceding 6 months, and residence in the capital city of the relevant jurisdiction for at least the last 12 months. Participants were recruited using multiple methods, including advertisements in newspapers, 
treatment agencies, needle and syringe programmes (NSPs) and peer referral. Participants were interviewed in locations convenient to them, such as NSPs, treatment agencies, public parks, coffee shops and hotels. The method of recruitment has remained consistent across years and jurisdictions.

The interview schedule was administered by research staff. Interviews took approximately $30-50$ minutes to complete. Participants in all jurisdictions except the ACT were reimbursed up to $\$ 30$ for their time and expenses incurred. In the ACT, money was provided to agencies that assisted with participant recruitment, and agency management redistributed a proportion of the fee to participants, either in cash or in kind. Informed consent was obtained prior to interview.

The structured interview schedule was based on previous NDARC studies of heroin and amphetamine users $[33,34]$. In 2004 , the questionnaire was amended in an attempt to collect greater detail on the illicit and licit use of pharmaceuticals and associated injectionrelated harms. Information on the price and availability of illicitly obtained morphine was also collected in 2004.

Each jurisdiction obtained ethics approval to conduct the study from the appropriate Ethics Committees in their jurisdiction.

\section{Data analysis}

Data were analysed using SPSS for Windows, release 13.0 (2004). Statistical tests were two-tailed, using a $5 \%$ level of significance. Continuous variables were analysed using $t$-tests, categorical variables using odds ratio (OR) with $95 \%$ confidence intervals (CI) and skewed data using the Mann-Whitney $U$-test.

\section{Results}

\section{Population trends in morphine prescription}

The rate of morphine prescriptions per person aged 15-54 years has increased between 1995 and 2003 across jurisdictions (Fig. 1), The amount of morphine being prescribed has also increased in this time, with an $89 \%$ increase in the average number of milligrams of morphine prescribed per person aged 15-54 years. The magnitude of the increase differed, however, across jurisdictions. In 1995, the rate of prescriptions was fairly similar across the country (between 41 and $62 \mathrm{mg}$ per person aged $15-54$ years). This was not the case in 2003 , with a range of $59-166 \mathrm{mg}$ per person aged 15-54 years. The changes in prescription rates occurred largely during the late 1990 s, with a stabilisation of rates during 2000-2003.

Differences in morphine prescription rates between jurisdictions were much larger than the differences

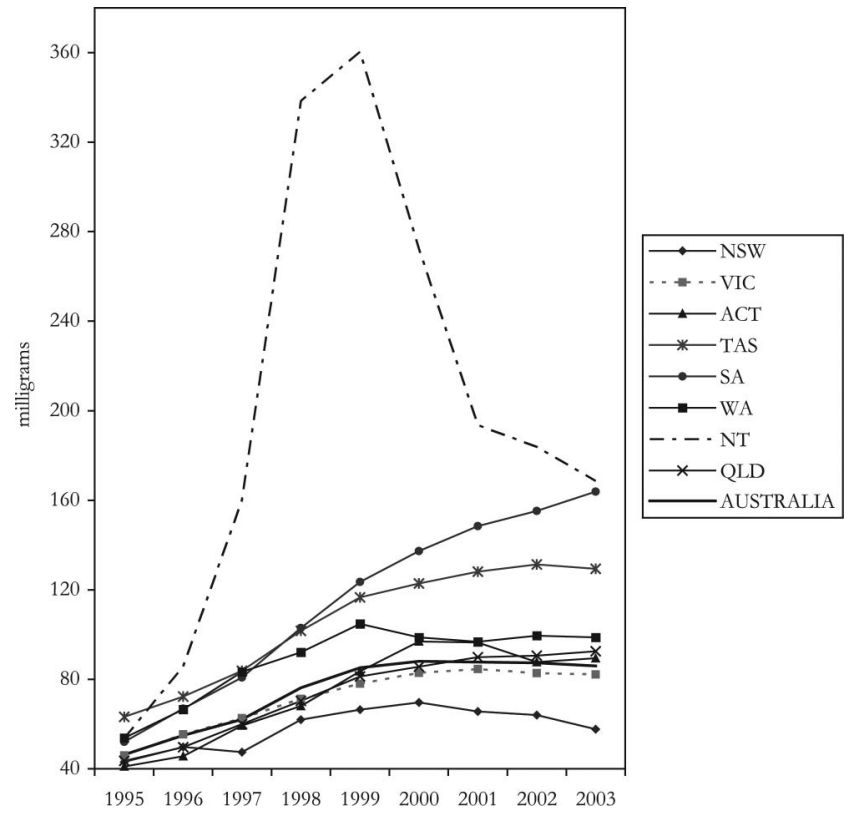

Figure 1. Milligrams of morphine prescribed per person aged 15-54 years by jurisdiction, 1995-2003. Note: includes 10, 15, 30, 60, 100 and $200 \mathrm{mg}$ controlled release tablets; 20, 50 and $100 \mathrm{mg}$ controlled release capsules; and $30 \mathrm{mg}$ tablets. $N S W=N e w$ South Wales; VIC = Victoria; ACT =Australian Capital Territory; $T A S=$ Tasmania; $S A=$ South Australia; WA =Western Australia; $N T=$ Northern Territory; $Q L D=$ Queensland.

within jurisdictions during the period $1995-2003$. The biggest change over time was in the NT, in which prescriptions increased by $507 \%$ between 1995 and 2000 and then fell $38 \%$ from 2000 to 2003 . This may be due to actions undertaken in the NT to constrain morphine prescription after the identification and monitoring of high prescribing GPs [35]. September 2002 also saw the introduction of methadone and buprenorphine maintenance treatment in the NT (previously these pharmacotherapies were only available for withdrawal treatment [27]).

Between 2000 and 2003, increases in the proportion of morphine prescribed as 100-200 mg tablets were observed in all jurisdictions except the ACT and the NT (see Fig. 2). As will be seen below, these are among the forms most favoured (and used) by IDU across the country. These data are therefore consistent with observations of increased morphine injection among the IDRS IDU samples in many jurisdictions.

\section{Trends among IDU}

Almost half (46\%) of the total IDU sample in 2004 had injected morphine within the past 6 months. The prevalence varied significantly by state, with the highest in the NT $(85 \%)$ followed by TAS $(60 \%)$, WA and QLD (45\%), the ACT and SA (40\%), VIC (41\%) and NSW $\left(22 \% ; \chi^{2}=115.05, p<0.001\right)$. Across all jurisdictions, 


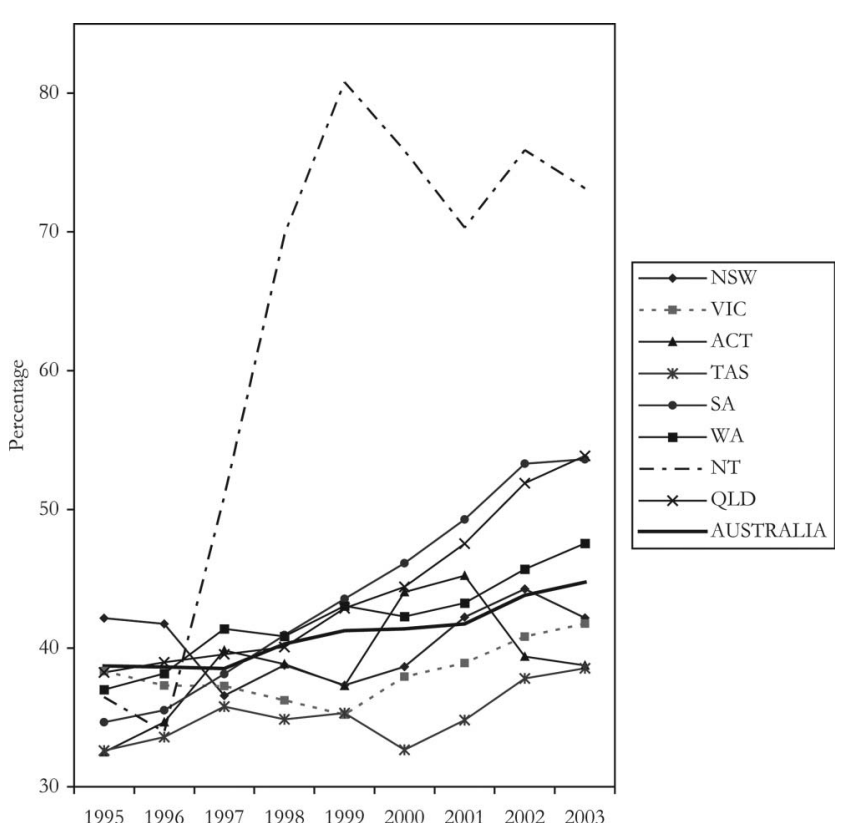

Figure 2. Percentage of milligrams of morphine prescribed that comprised doses of 100-200 mg by jurisdiction, 1995-2003. Note: includes 10, 15, 30, 60, 100 and $200 \mathrm{mg}$ controlled release tablets; 20, 50 and $100 \mathrm{mg}$ controlled release capsules; and $30 \mathrm{mg}$ tablets.

those IDU who reported injecting morphine had injected it on a median of 12 days in the past 6 months.

In 2004, most IDU reported that they had usually obtained their morphine illicitly (i.e. it had not been directly prescribed to them). The proportion reporting that they had predominantly used diverted morphine (rather than morphine directly prescribed to them) in the past 6 months ranged from around two-thirds in SA (68\%) to almost all the IDU (97\%) in TAS (specifically, $73 \%$ in NT, $83 \%$ in VIC, $84 \%$ in NSW, $87 \%$ in ACT, $89 \%$ in WA and $93 \%$ in QLD).

Similarly, the majority of the 2004 IDU sample who had recently used morphine reported that they had bought $100 \mathrm{mg}$ doses illicitly in the past 6 months. The proportion reporting buying this dose ranged from $59 \%$ in VIC to $87 \%$ in NT (specifically, $68 \%$ in ACT, $72 \%$ in TAS, $73 \%$ in NSW, $82 \%$ in QLD, $83 \%$ in SA and $86 \%$ in WA).

Examination of drug use patterns across jurisdictions revealed some interesting patterns (Fig. 3). In those jurisdictions where heroin use was prevalent (e.g. NSW and VIC), morphine use was lower; in contrast, those jurisdictions with higher rates of morphine use (e.g. NT and TAS) had lower rates of heroin use. These trends were consistent across study years (2000-2004).

\section{Demographics}

In 2004, recent morphine injectors were significantly more likely to be male, unemployed and homeless in comparison to IDU who had not injected morphine (Table 1). They were also significantly less likely to be engaged in drug treatment, including pharmacotherapy, or to have completed 10 years of schooling.

\section{Drug use history}

In 2004, IDU reporting recent morphine injection had first injected at a younger age than IDU reporting recent heroin (but not morphine) injection (Table 2). Recent morphine injectors were more likely to report initiation to injecting with morphine or methamphetamine and two times less likely to report initiation with heroin, with a similar pattern observed in their nominated drug of choice. Recent morphine injectors were significantly less likely to report recent injection of heroin, and were more likely to have used a greater number of drug types over the preceding 6 months than IDU reporting recent injection of heroin but not morphine.

A significant bivariate association was found between morphine injection and polydrug injection in the 6 months preceding interview, with $66 \%$ of morphine injectors being classified as 'polydrug injectors' compared to $35 \%$ of those who did not report morphine injection ( $\mathrm{OR}=4.58,95 \% \mathrm{CI}=3.48-6.04)$. Recent morphine injectors therefore reported using a greater number of drugs, so it was also of interest to establish whether they also injected more frequently. [Polydrug injection was defined as injection of three or more drug classes in the preceding 6 months. Drug classes were: opioids (including heroin, morphine, homebake and other opioids), methadone (including Physeptone), amphetamines (including speed, base, ice, liquid amphetamine and pharmaceutical stimulants), cocaine, hallucinogens, ecstasy, benzodiazepines and buprenorphine.]

A stepwise binary logistic regression was conducted to determine predictors of daily injection in the month preceding interview in the 2004 sample (Fig. 4). Jurisdiction of residence was associated significantly with daily injection, with IDU in NSW (OR $=3.20,95 \%$ $\mathrm{CI}=1.86-5.50)$, VIC $(\mathrm{OR}=2.06,95 \% \mathrm{CI}=1.20-$ 3.54), WA $(\mathrm{OR}=2.04,95 \% \mathrm{CI}=1.09-3.79)$ and $\mathrm{NT}$ $(\mathrm{OR}=2.46,95 \% \mathrm{CI}=1.37-4.43)$ significantly more likely to inject daily than IDU in QLD and other jurisdictions. IDU who reported current engagement in any form of drug treatment were significantly less likely than those who were not in treatment to report daily drug injection $(\mathrm{OR}=0.34,95 \% \mathrm{CI}=0.25-0.46)$. After controlling for the above variables, recent morphine use and injection were not significantly associated with daily drug injection in the preceding month.

\section{Injection-related harms}

In 2004, levels of risk-taking behaviours in the preceding month (borrowing and lending of needles, 

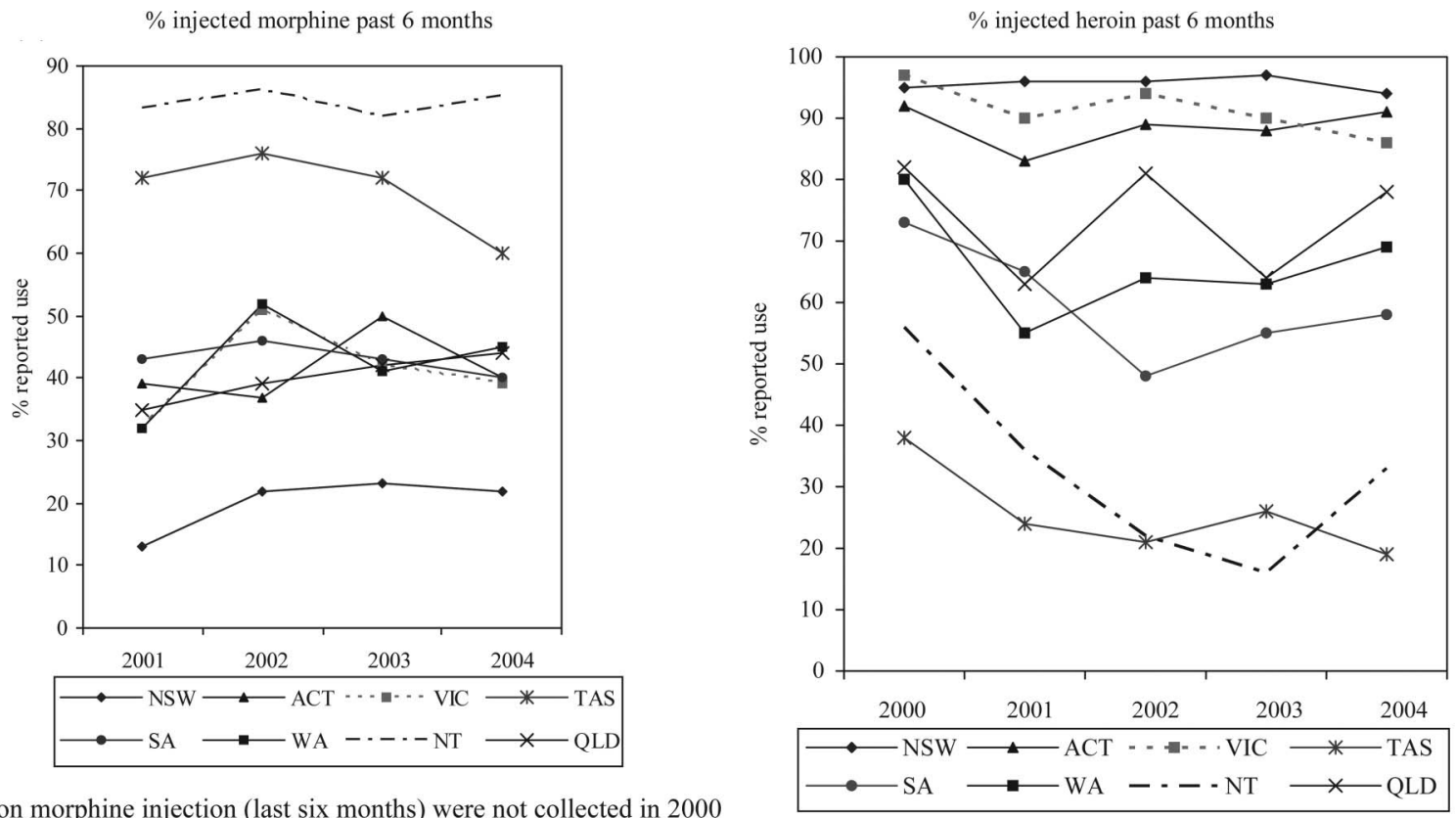

*Data on morphine injection (last six months) were not collected in 2000
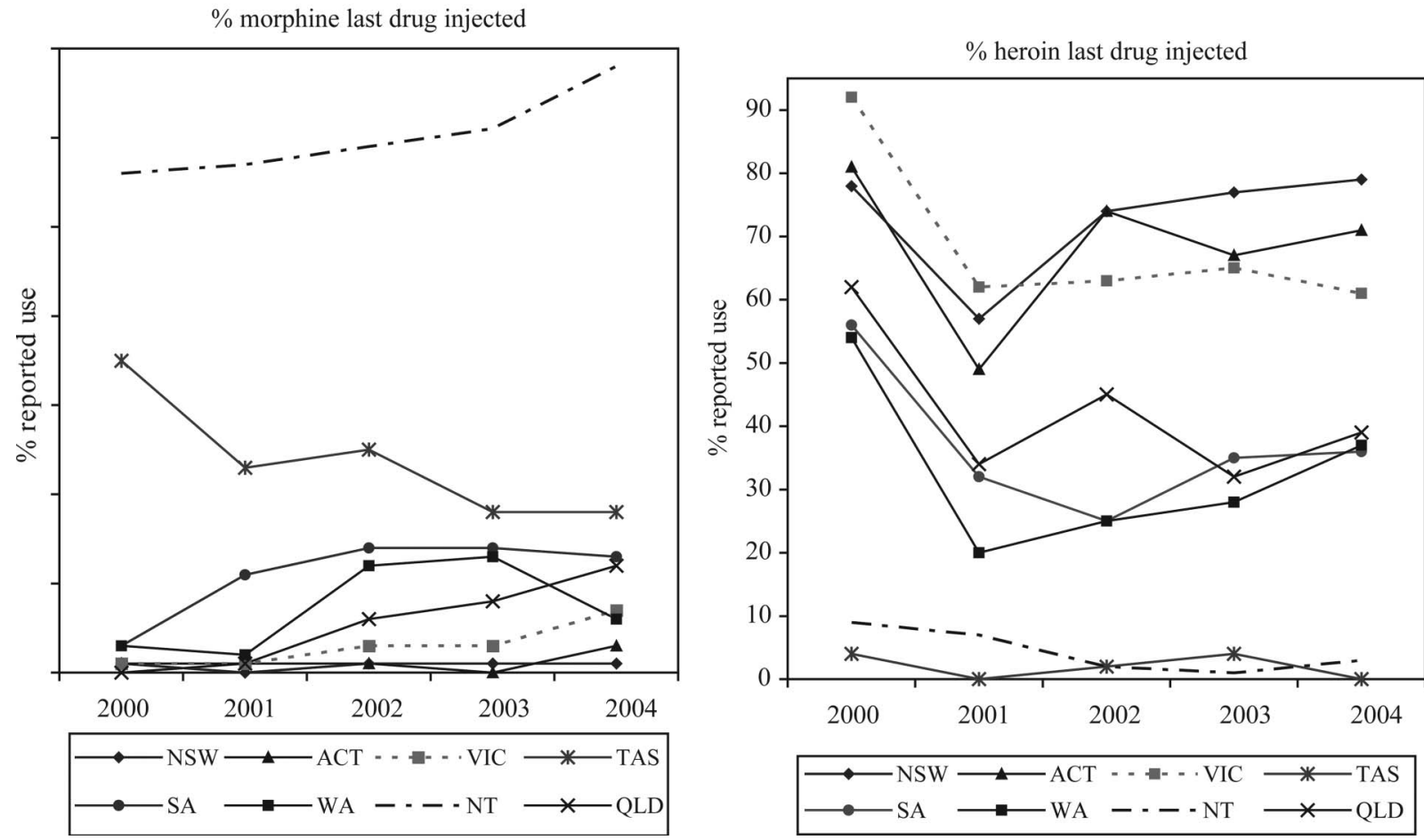

Figure 3. Patterns of morphine and heroin use among IDU in the past 6 months by jurisdiction, 2000-2004.*

injection in public places) were similar in both groups (Table 3). Recent morphine injectors were more likely to report experiencing injection-related problems in the preceding month $(77 \%$ vs. $66 \%)$. They were also more likely to report engaging in crime in the last month and to have been arrested in the last 12 months.

Among those IDU in the 2004 sample who had injected morphine recently, the most commonly reported morphine-related injecting harms were self- reported morphine dependence (38\%), difficulty finding veins into which to inject $(36 \%)$ and scarring/bruising $(27 \%)$. Just under a third (29\%) reported experiencing no morphine-related injecting harms in the month preceding interview. Recent morphine injectors were equally as likely as IDU who had injected heroin (but not morphine) in the preceding 6 months to have experienced a heroin overdose in their lifetime; however, they had on average experienced an overdose on fewer 
Table 1. Demographic characteristics of IDU according to recent morphine injection, 2004

\begin{tabular}{lccc}
\hline & $\begin{array}{c}\text { Injected heroin but } \\
\text { not morphine } n=360\end{array}$ & $\begin{array}{c}\text { Recent morphine } \\
\text { injectors }{ }^{1} n=435\end{array}$ & $\begin{array}{c}\text { OR (95\% CI) or } \\
t(p \text { value })\end{array}$ \\
\hline Age (M) & 33.5 & 34 & $\mathrm{~ns}$ \\
\% Male & 59 & 73 & $1.81(1.35-2.44)$ \\
Years education (M) & 10.2 & 9.9 & $2.485(p<0.05)$ \\
\% Unemployed & 74 & 81 & $1.49(1.06-2.08)$ \\
\% Criminal activity main income past month & 7 & 9 & $\mathrm{~ns}$ \\
\% Prison history & 47 & 50 & $\mathrm{~ns}$ \\
\% In drug treatment & 58 & 38 & $0.44(0.33-0.59)$ \\
\% Pharmacotherapy & 57 & 33 & $0.38(0.29-0.51)$ \\
\% Homeless & 5 & 12 & $2.74(1.55-4.83)$
\end{tabular}

${ }^{1}$ These users may also have used heroin.

occasions. The rate of lifetime morphine overdose was relatively low in comparison to heroin overdose (6\% vs. $56 \%)$.

A stepwise binary logistic regression was conducted to determine predictors of injection site-related problems (abscesses or infections, difficulty injecting and/ or prominent scarring or bruising) in the month preceding interview among the 2004 sample. Variables accounted for in the regression model included: gender, age, jurisdiction, current treatment (any form), homelessness, unemployment, polydrug use, daily frequency of injection and morphine (vs. heroin only) injection. Recent injection of three or more drug classes was predictive of injection problems $(\mathrm{OR}=2.50,95 \%$ $\mathrm{CI}=1.81-3.45)$, as was being female $(\mathrm{OR}=0.49,95 \%$ $\mathrm{CI}=0.35-0.70)$. IDU who were currently unemployed were significantly more likely to report injection site problems $(\mathrm{OR}=0.62,95 \% \mathrm{CI}=0.42$ 0.92). Jurisdiction of interview was also a significant predictor of injection site problems, with a greater proportion of IDU in the NT reporting such issues $(\mathrm{OR}=2.16,95 \% \mathrm{CI}=1.16-4.01)$ than IDU in other jurisdictions. Recent morphine injection was not significantly associated with injection site problems in this regression.

\section{Discussion}

\section{Population trends in morphine prescriptions}

There have been considerable changes in the extent of morphine prescribing in Australia since 1995. The magnitude of these changes has differed markedly across jurisdictions, and the increases seem to have occurred largely in the late 1990s. One potential reason for increases in population-level morphine prescribing is the ageing of the Australian population [36], and with it, an increased need for medications related to palliative care and the treatment of pain related to various illnesses of older age. Moderate and continued increases in population levels of prescribing would therefore be expected. However, as the only explanation of these changes, this is insufficient. First, the magnitude of the increases in the rate of morphine prescribed differed between jurisdictions; secondly, the extent of prescribing also differed between jurisdictions; thirdly, the increases were neither smooth nor constant; and fourthly, there were sharp increases in the prescription of high-dose morphine forms (100-200 $\mathrm{mg}$ doses), which suggests that those receiving the doses had considerable tolerance to the drug. Part of these changes may reflect an increase in rates of long-term morphine prescriptions, and hence higher dosages prescribed to patients who have developed high tolerance. There is evidence from some jurisdictions of marked increases in applications for narcotic prescription beyond acute contexts over the past 10 years (e.g. [37]). This suggests that multiple factors may have been contributing to the changes in morphine prescribing in Australia.

The combination of prescription data with data from sentinel groups of injecting drug users allowed investigation into the possibility that observed changes in prescription practices may be due partially to changes in use among people obtaining morphine for illicit use. Consistent with this, in jurisdictions where morphine prescription rates were higher (particularly the NT, for example), so too were rates of morphine use among IDU. Furthermore, IDU often reported that high-dose morphine preparations were those that they used most often.

\section{Morphine use among injecting drug users}

Changes over time in injection of morphine and heroin illustrate the interdependence of illicit drug markets in Australia. One factor which may have contributed to a recent increase in morphine injection was a sustained reduction in the availability of heroin across the country from 2001 [38]. Compared to heroin, diverted morphine may be seen as a comparatively 'safe', affordable 
Table 2. Drug use history of IDU according to morphine injection in the preceding 6 months, 2004

\begin{tabular}{|c|c|c|c|}
\hline & $\begin{array}{l}\text { Heroin but not } \\
\text { morphine } n=360\end{array}$ & $\begin{array}{l}\text { Recent morphine } \\
\text { injectors }{ }^{2} n=435\end{array}$ & $\begin{array}{c}\text { OR }(95 \% \mathrm{CI}) \text { or } \\
t(p \text { value })\end{array}$ \\
\hline Age first injected (M) & 19.7 & 18.9 & $1.98(p=0.048)$ \\
\hline \multicolumn{4}{|l|}{$\%$ first drug injected } \\
\hline Heroin & 55 & 37 & $0.47(0.35-0.62)$ \\
\hline Methamphetamine & 39 & 50 & $1.56(1.18-2.08)$ \\
\hline Morphine & 1 & 7 & $5.26(2.02-13.8)$ \\
\hline \multicolumn{4}{|l|}{$\%$ drug of choice } \\
\hline Heroin & 78 & 55 & $0.35(0.25-0.47)$ \\
\hline Methamphetamine & 8 & 18 & $2.40(1.56-3.81)$ \\
\hline Morphine & $<1$ & 12 & $23.25(5.62-96.24)$ \\
\hline \multicolumn{4}{|l|}{ Heroin } \\
\hline$\%$ Injected last 6 months & 100 & 67 & $2.24(2.05-2.44)$ \\
\hline Median days injected ${ }^{1}$ & 72 & 48 & $U=45321^{*}$ \\
\hline \multicolumn{4}{|l|}{ Morphine } \\
\hline$\%$ Injected last 6 months & & 100 & \\
\hline Median days injected ${ }^{1}$ & & 12 & \\
\hline \multicolumn{4}{|l|}{ Cocaine } \\
\hline$\%$ Injected last 6 months & 13 & 12 & ns \\
\hline Median days injected ${ }^{1}$ & 12 & 2 & $U=754^{* *}$ \\
\hline \multicolumn{4}{|l|}{ Methamphetamine (ice) } \\
\hline \% Injected last 6 months & 39 & 56 & $1.97(1.48-2.619)$ \\
\hline Median days injected ${ }^{1}$ & 4 & 10 & $U=14658^{*}$ \\
\hline \multicolumn{4}{|l|}{ Methamphetamine (base) } \\
\hline$\%$ Injected last 6 months & 22 & 43 & $2.73(1.99-3.73)$ \\
\hline Median days injected ${ }^{1}$ & 6 & 6 & ns \\
\hline \multicolumn{4}{|l|}{ Methamphetamine (speed) } \\
\hline$\%$ Injected last 6 months & 38 & 60 & $2.42(1.82-3.23)$ \\
\hline Median days injected ${ }^{1}$ & 6 & 7 & ns \\
\hline \multicolumn{4}{|l|}{ Benzodiazepines } \\
\hline$\%$ Injected last 6 months & 11 & 19 & $2.00(1.33-3.03)$ \\
\hline Median days injected ${ }^{1}$ & 2 & 12 & $U=1010^{* *}$ \\
\hline \multicolumn{4}{|l|}{ Alcohol } \\
\hline$\%$ Used last 6 months & 63 & 71 & $1.45(1.08-1.96)$ \\
\hline Median days used ${ }^{1}$ & 12 & 15 & ns \\
\hline \multicolumn{4}{|l|}{ Buprenorphine: prescribed } \\
\hline$\%$ Injected last 6 months & 11 & 8 & ns \\
\hline Median days injected ${ }^{1}$ & 14 & 10 & ns \\
\hline \multicolumn{4}{|l|}{ Buprenorphine: illicit } \\
\hline$\%$ Injected last 6 months & 7 & 20 & $3.10(1.95-4.94)$ \\
\hline Median days injected ${ }^{1}$ & 3 & 5 & ns \\
\hline \multicolumn{4}{|l|}{ Methadone: prescribed } \\
\hline \% Injected last 6 months & 10 & 14 & ns \\
\hline Median days injected ${ }^{1}$ & 48 & 48 & ns \\
\hline \multicolumn{4}{|l|}{ Methadone: illicit } \\
\hline$\%$ Injected last 6 months & 13 & 30 & $2.97(2.05-4.31)$ \\
\hline Median days injected ${ }^{1}$ & 4 & 5 & ns \\
\hline \multicolumn{4}{|l|}{ Physeptone: prescribed } \\
\hline$\%$ Injected last 6 months & $<1$ & 3 & $4.67(1.03-1.19)$ \\
\hline Median days injected ${ }^{1}$ & 15 & 48 & ns \\
\hline \multicolumn{4}{|l|}{ Physeptone: illicit } \\
\hline$\%$ Injected last 6 months & 2 & 18 & $9.29(4.42-19.53)$ \\
\hline Median days injected ${ }^{1}$ & 6 & 6 & $\mathrm{~ns}$ \\
\hline \multicolumn{4}{|l|}{ Other opioids } \\
\hline$\%$ Injected last 6 months & 3 & 10 & $4.50(2.17-9.34)$ \\
\hline Median days injected ${ }^{1}$ & 5 & 4 & ns \\
\hline$\%$ Daily or more injecting past month & 47 & 52 & ns \\
\hline No. drug classes used past 6 months (M) & 6 & 8 & $-12.23 * *$ \\
\hline No. drug classes injected past 6 months (M) & 2 & 4 & $-17.42 * *$ \\
\hline
\end{tabular}

${ }^{1}$ Among those who had used the drug; ${ }^{2}$ these users may also have used heroin. ${ }^{*} p<0.01 ;{ }^{* *} p<0.001$. 
and reliably available choice by IDU, with the additional advantage that it has a known level of purity.

The injection of morphine among this group appeared to be associated with a number of factors. First, those IDU who were injecting morphine appeared to be a more disadvantaged group, with

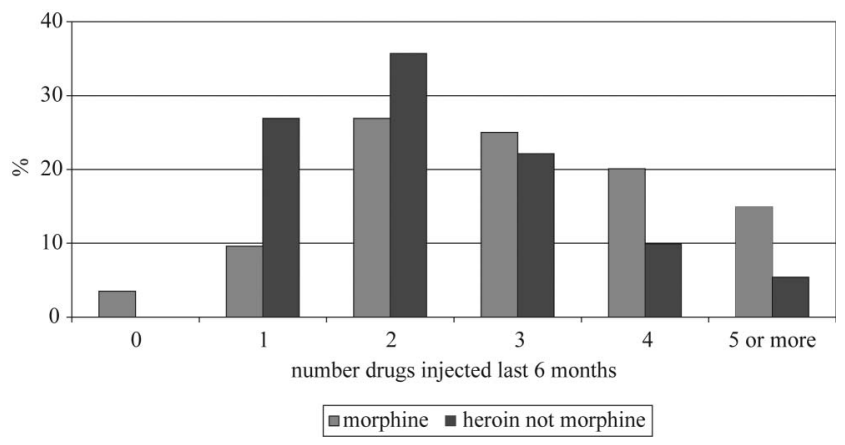

Figure 4. Polydrug injection, 2004. Note: Excludes morphine; different forms of the same drug type were classified as one drug type (e.g. methamphetamine powder/base methamphetamine/crystal methamphetamine). higher rates of homelessness, unemployment and lower rates of treatment for their drug use than those who did not inject morphine. Secondly, they appeared to be more entrenched drug users, with injection careers that began earlier, greater drug use and injection of a greater number of drug types. Thirdly, this group appeared more likely to use a range of prescription drugs, and to inject a range of other non-injectables such as methadone, benzodiazepines and buprenorphine. Not surprisingly, then, they also reported more harms related to their injecting drug use. Finally, a significant proportion of morphine injectors (38\%) reported experiencing dependence upon morphine.

Given these findings, there appears to be a strong need for a range of public health responses. First, reasons for changes in the extent of morphine prescribing need to be examined in greater depth. This might include an examination (as discussed above) of potential changes in prescription practices among general practitioners or the ageing of the Australian population, for example. The relative harm associated with injection of morphine compared with alternative opiates available to IDU in Australia should be considered in this debate.

Table 3. Harms and risk-taking behaviours according to morphine injection in the preceding 6 months, 2004

\begin{tabular}{|c|c|c|}
\hline & $\begin{array}{l}\text { Heroin only } \\
\text { injectors } \\
n=357\end{array}$ & $\begin{array}{c}\text { Recent morphine } \\
\text { injectors } \\
n=434\end{array}$ \\
\hline$\%$ Borrowed needles in past month & 12 & 11 \\
\hline$\%$ Lent needles in past month & 17 & 18 \\
\hline$\%$ Last injected in public place in past month & 29 & 21 \\
\hline$\%$ Usually injected in public place in past month & 18 & 12 \\
\hline$\%$ Injection-related problems past month & 66 & 77 \\
\hline$\%$ Attended mental health professional past 6 months & 45 & 44 \\
\hline$\%$ Any crime in past month & 42 & 53 \\
\hline$\%$ Arrested in past 12 months & 39 & 46 \\
\hline \multicolumn{3}{|l|}{$\%$ Reporting past month morphine-related injecting harms ${ }^{2}$} \\
\hline Morphine dependence & & 38 \\
\hline Difficulty finding veins & & 36 \\
\hline Scarring/bruising & & 27 \\
\hline Swelling of arm & & 19 \\
\hline Swelling of hand & & 11 \\
\hline Dirty hit & & 11 \\
\hline Swelling of feet & & 9 \\
\hline Abscesses/infections & & 5 \\
\hline Thrombosis/blood clot & & 2 \\
\hline Swelling of leg & & 2 \\
\hline Hospitalisation & & 1 \\
\hline Contact with ambulance/police & & 1 \\
\hline Gangrene & & $<1$ \\
\hline None & & 29 \\
\hline$\%$ Reporting lifetime morphine overdose & & 6 \\
\hline$\%$ Reporting lifetime heroin overdose & 59 & 56 \\
\hline Number of heroin overdoses (median) ${ }^{3}$ & 3 & 1 \\
\hline
\end{tabular}

${ }^{1}$ These users may also have used heroin; ${ }^{2}$ asked of participants who injected morphine in the last month only; ${ }^{3}$ among those who had ever overdosed. 
Secondly, the diversion of morphine for use for nonmedical purposes also needs to be reduced through appropriate supply and demand reduction initiatives. There needs to be an examination of the methods through which IDU are obtaining morphine: 'doctorshopping', selling-on of prescriptions, theft and access via the internet are some ways this may occur. The ways in which interventions are targeted would differ according to the method of obtainment.

Thirdly, as can be seen from the NT example, some medical practitioners may be inclined to provide 'informal' opioid maintenance treatment for dependent people if public programmes such as methadone and buprenorphine maintenance are unavailable. In the absence of demand reduction initiatives such as treatment provision, reduced supply of such 'maintenance' morphine might increase the extent of harm among this group - it has been suggested that in the absence of opioid pharmacotherapy within the health-care system, the provision of morphine at maintenance levels might be protective against harm among opioid-dependent IDU $[39,40]$.

Fourthly, there is a need to address more effectively the needs of this group of IDU. The majority are not receiving traditional drug treatment, and as they appear to be a more socially marginalised group they may be in greater need of a range of social services. They also potentially have more complex drug problems as they report using a greater range of drug types and often report morphine dependence. In the interim, given continued diversion and injection of morphine, there is a need to develop palatable and relevant harm reduction messages for this group.

Fifthly, there is a need to examine morphine prescribing practices further around the country to determine the context and reasons for the increase in morphine prescription.

Finally, it is important to remember that opioid medications such as morphine serve important roles in the context of pain management [41], and so there is a need to ensure a balance between both minimising prescription opioid diversion and prescription access for licit medical purposes [18].

\section{Conclusion}

Morphine use and injection is a common practice among regular IDU in Australia. In some cases, morphine may be a substitute for illicit heroin; in others, it may be being used as a form of treatment for heroin dependence where other pharmacotherapies, such as methadone and buprenorphine, are perceived as being unavailable or undesirable by IDU. Morphine injection appears to be associated with polydrug use and, with it, a range of injection related problems. Further research is required to monitor and reduce the diversion of morphine and its associated harms within this group.

\section{Acknowledgements}

The Illicit Drug Reporting System is funded by the Australian Government Department of Health and Ageing (AGDHA) and the National Drug Law Enforcement Research Fund (NDLERF). In addition to the authors, the following researchers and research institutions contributed to the data collected for this study: Mr Chris Moon and Ms Jaclyn Newman, Department of Health and Community Services, Northern Territory; Professor Jake Najman, Queensland Alcohol and Drug Research and Education Centre, University of Queensland; Associate Professor Stuart McLean, School of Pharmacy, University of Tasmania; Dr Sophie Pointer, Drug and Alcohol Services South Australia; Ms Kirsten Buckingham, Ms Phoebe Proudfoot and Mr Randolph Sparks, Australian National University, Australian Capital Territory; and Dr Simon Lenton, National Drug Research Institute, Curtin University, Western Australia. Cheryl Regan, from the Treaties and Monitoring section of OCS/TGA provided DRUMS data on morphine prescriptions. Mr Stuart Gilmour provided patient statistical advice. We thank the agencies and individuals who assisted with recruitment and interviewing of IDU. Finally, we thank the IDU who were willing to be interviewed and share their experience.

\section{References}

[1] Office of Applied Studies-Substance Abuse and Mental Health Services Administration. Emergency department trends from DAWN: final estimates 1995-2002. DAWN Series D-24, DHHS publication no. (SMA) 03-3780. Rockville, MD: USA Department of Health and Human Services, 2003.

[2] Johnston LD, O’Malley PM, Bachman JG. National survey results on drug use from the Monitoring the Future study, 1975-2003. Rockville, MD: National Institute on Drug Abuse, 2003.

[3] McCabe SE, Teter C, Boyd CJ. Illicit use of prescription pain medication among college students. Drug Alcohol Depend 2005;77:37-47.

[4] Fry C, Bruno R. Recent trends in benzodiazepine use by injecting drug users in Victoria and Tasmania. Drug Alcohol Rev 2002;21:363-7.

[5] Breen C, Degenhardt L, Bruno R, Roxburgh A, Jenkinson R. The impact of the restriction of publicly subsidised $10 \mathrm{mg}$ temazepam capsules upon benzodiazepine use among injecting drug users in Australia. Med J Aust 2004;181:300 - 5.

[6] Iguchi MY, Handelsman L, Bickel WK, Griffiths RR. Benzodiazepine and sedative use/abuse by methadone maintenance clients. Drug Alcohol Depend 1993;32:257-66.

[7] Dupont RL. Abuse of benzodiazepines: the problems and the solutions. Am J Drug Alcohol Abuse 1998;14(suppl. 1): $1-69$. 
[8] Strang J, Griffiths P, Abbey J, Gossop M. Survey of injected benzodiazepines among drug users in Britain. BMJ 1994; 308:1082.

[9] Darke S, Ross J, Hall W. Prevalence and correlates of the injection of methadone syrup in Sydney, Australia. Drug Alcohol Depend 1996;43:191-8.

[10] Lintzeris N, Lenne M, Ritter A. Methadone injecting in Australia: a tale of two cities. Addiction 1999;94:1175-8.

[11] Tacke U. Abuse of buprenorphine by intravenous injection-the French connection[comment]. Addiction 2002;97:1355.

[12] Obadia Y, Perrin V, Feroni I, Vlahov D, Moatti JP. Injecting misuse of buprenorphine among French drug users. Addiction 2001;96:267-72.

[13] Valenciano M, Emmanuelli J, Lert F. Unsafe injecting practices among attendees of syringe exchange programmes in France [see comment]. Addiction 2001;96:597-606.

[14] Darke S, Ross J, Zador D, Sunjic S. Heroin-related deaths in New South Wales, Australia, 1992-1996. Drug Alcohol Depend 2000;60:141-50.

[15] Auriacombe M, Franques P, Tignol J. Deaths attributable to methadone vs. buprenorphine in France. JAMA 2001; 285:3.

[16] Oliver P, Keen J, Rowse G, Mathers N. Deaths from drugs of abuse in Sheffield, 1998: the role of prescribed medication. Br J Gen Pract 2001;51:394-6.

[17] Bedford KR, Nolan SL, Onrust R, Siegers JD. The illicit preparation of morphine and heroin from pharmaceutical products containing codeine: 'homebake' laboratories in New Zealand. Forensic Sci Int 1987;34:197-204.

[18] Zacny J, Bigelow G, Compton P, Foley K, Iguchi MY, Sannerud C. College on Problems of Drug Dependence taskforce on prescription opioid non-medical use and abuse: position statement. Drug Alcohol Depend 2003;69:215-32.

[19] Hando J, O'Brien S, Darke S, Maher L, Hall W. The Illicit Drug Reporting System trial: final report. Monograph no. 31. Sydney: National Drug and Alcohol Research Centre, University of New South Wales, 1997.

[20] Bruno R, Mclean S. Tasmanian Drug Trends 2003: findings from the Illicit Drug Reporting System (IDRS). NDARC Technical Report no. 178. Sydney: National Drug and Alcohol Research Centre, University of New South Wales, 2004.

[21] Moon C. Northern Territory Drug Trends 2003: findings from the Illicit Drug Reporting System (IDRS). NDARC Technical Report no. 181. Sydney: National Drug and Alcohol Research Centre, University of New South Wales, 2004.

[22] Breen C, Degenhardt L, Roxburgh A, et al. Australian drug trends 2003: findings from the Illicit Drug Reporting System (IDRS). NDARC Monograph no. 50. Sydney: National Drug and Alcohol Research Centre, University of NSW, 2004.

[23] Roxburgh A, Breen C, Degenhardt L. New South Wales drug trends 2003: findings from the Illicit Drug Reporting System (IDRS). NDARC Technical Report no. 174. Sydney: National Drug and Alcohol Research Centre, University of New South Wales, 2004.

[24] Jenkinson R, Miller P, Fry C. Victorian Drug Trends 2003: findings from the Illicit Drug Reporting System (IDRS). NDARC Technical Report no. 175. Sydney: National Drug and Alcohol Research Centre, University of New South Wales, 2004.

[25] Jenkinson R, Clark N, Fry C, Dobbin M. Buprenorphine diversion and injection in Melbourne, Australia: an emerging issue? Addiction 2005;100:197-205.
[26] Darke S, Topp L, Ross J. The injection of methadone and benzodiazepines among Sydney IDU 1996-2000: 5-year monitoring of trends from the Illicit Drug Reporting System (IDRS). Drug Alcohol Rev 2002;21:27-32.

[27] Breen C, Degenhardt L, Roxburgh A, et al. Australian drug trends 2002: findings from the Illicit Drug Reporting System (IDRS). NDARC Monograph no. 50. Sydney: National Drug and Alcohol Research Centre, University of NSW, 2003.

[28] McKetin R, Darke S, Humeniuk R, et al. Australian drug trends 1999: findings from the Illicit Drug Reporting System (IDRS). NDARC Monograph no. 43. Sydney: National Drug and Alcohol Research Centre, University of New South Wales, 2000.

[29] Stafford J, Degenhardt L, Black E, et al. Australian drug trends 2004: findings from the Illicit Drug Reporting System (IDRS). NDARC Monograph no. 55. Sydney: National Drug and Alcohol Research Centre, University of New South Wales, 2005.

[30] Topp L, Barker B, Degenhardt L. The external validity of results derived from ecstasy users recruited using purposive sampling strategies. Drug Alcohol Depend 2004;73:33-40.

[31] Topp L, Darke S, Bruno R, et al. Australian drug trends 2000: findings from the Illicit Drug Reporting System (IDRS). NDARC Monograph no. 47. Sydney: National Drug and Alcohol Research Centre, University of New South Wales, 2001.

[32] Topp L, Kaye S, Bruno R, et al. Australian Drug Trends 2001. Findings from the Illicit Drug Reporting System (IDRS). NDARC Monograph no. 48. Sydney: National Drug and Alcohol Research Centre, University of New South Wales, 2002.

[33] Darke S, Hall W, Wodak A, Heather N, Ward J. Development and validation of a multi-dimensional instrument for assessing outcomes of treatment among opiate users: the Opiate Treatment Index. Br J Addict 1992;87:733-42.

[34] Darke S, Cohen J, Ross J, Hando J, Hall W. Transitions between routes of administration of regular amphetamine users. Addiction 1994;89:1683-90.

[35] O'Reilly B, Rysavy P. Northern Territory drug trends 2000: findings of the Illicit Drug Reporting System. Sydney: National Drug and Alcohol Research Centre, University of New South Wales, 2001.

[36] Australian Bureau of Statistics. 3222.0 population projections, Australia 2002-2101. Canberra: Australian Government Printing Service, 2003.

[37] Bruno R. Tasmanian drug trends 2004: findings from the Illicit Drug Reporting System (IDRS). NDARC Technical Report no. 215. Sydney: National Drug and Alcohol Research Centre, University of New South Wales, 2005.

[38] Day C, Degenhardt L, Hall W. Documenting the heroin shortage in New South Wales. Drug Alcohol Rev 2006;25: $297-305$.

[39] O'Reilly B, Leibrick F, Chenhall R. An exploration of the crime and policing implications of an illicit opiate market dominated by prescription morphine. In: 15th International Conference on the Reduction of Drug Related Harm, Melbourne, Australia, 2004.

[40] O'Reilly B. Northern Territory drug trends 2001: findings of the Illicit Drug Reporting System. NDARC Technical Report no. 137. Sydney: National Drug and Alcohol Research Centre, University of New South Wales, 2002.

[41] World Health Organization. Achieving balance in national opioids control policy. Guidelines for assessment. Geneva, Switzerland: World Health Organization, 2000. 